\title{
Editorial
}

\author{
Maria do Carmo Duarte Freitas ${ }^{1}$, Paula Carina de Araújo², Helza Ricarte Lanz ${ }^{3}$ \\ ${ }^{1}$ Universidade Federal do Paraná (UFPR), Curitiba, Paraná, Brasil. ORCID: https://orcid.org/000-0002-7046-6020 \\ 2 Universidade Federal do Paraná (UFPR), Curitiba, Paraná, Brasil. ORCID: http://orcid.org/0000-0003-4608-752X \\ ${ }^{3}$ Universidade de Colônia, Colônia, Alemanha. ORCID: https://orcid.org/000-002-6739-2868
}

Autor para correspondência/Mail to: Maria do Carmo Duarte Freitas, revistaatoz@ufpr.br

Copyright (C) 2021 Freitas, Araújo \& Lanz. Todo o conteúdo da Revista (incluindo-se instruções, política editorial e modelos) está sob uma licença Creative Commons Atribuição 4.0 Internacional. Ao serem publicados por esta Revista, os artigos são de livre uso em ambientes educacionais, de pesquisa e não comerciais, com atribuição de autoria obrigatória. Mais informações em http://revistas.ufpr.br/atoz/about/submissions\#copyrightNotice.

\section{ESTUDOS QUALITATIVOS E TECNOLOGIAS APLICADAS À GESTÃO DA INFORMAÇÃO E DO CONHECIMENTO}

Iniciamos 2021 ainda vivenciando os problemas da pandemia e na expectativa de vencer os desafios que ela nos impõe. Faz exatamente um ano que as portas da maioria das instituições foram fechadas e começamos a trabalhar de forma remota. Abrimos nossas casas e passamos a conciliar atividades do lar com o mundo profissional. No entanto, nossas atividades continuaram e nos abrimos ao diálogo a distância fortemente apoiados na tecnologia.

As tecnologias de informação e comunicação contribuem de diferentes formas nas relações sociais, no entretenimento, na educação e no trabalho. No mundo do trabalho, atua de forma diferente com mais flexibilidade e liberdade, além de tornar a comunicação fluida e eficiente. É essa tecnologia que nos permite partilhar nossas ideias e pesquisas que realizamos. Para nós, equipe da AtoZ, não foi diferente! Por incrível que pareça, crescemos de diferentes maneiras: temos mais colaboradores, tanto na edição quanto pesquisadores na avaliação - aqui expressamos a gratidão pelo voluntariado; passamos a receber mais artigos nacionais e internacionais, que nos levou a tornar a revista quadrimestral e em fluxo contínuo; e inovamos nas redes sociais com marketing científico, que propicia visibilidade à revista, aos pesquisadores e ao conhecimento científico gerado nos diferentes grupos de pesquisa e instituições que nos prestigiam com resultados de suas investigações.

Este número da AtoZ traz pesquisas com ênfase em três das nove temáticas de interesse relacionadas em nosso escopo. Temos artigos que apresentam "Estudos qualitativos e quantitativos orientados à informação e ao conhecimento", "Tecnologias aplicadas a sistemas, produtos e serviços de informação e de conhecimento" e "Gestão de informação e do conhecimento em organizações públicas, privadas ou de terceiro setor". Reunidos nos diferentes artigos de 26 pesquisadores, pertencentes a 15 instituições e que representam 11 estados da federação brasileira.

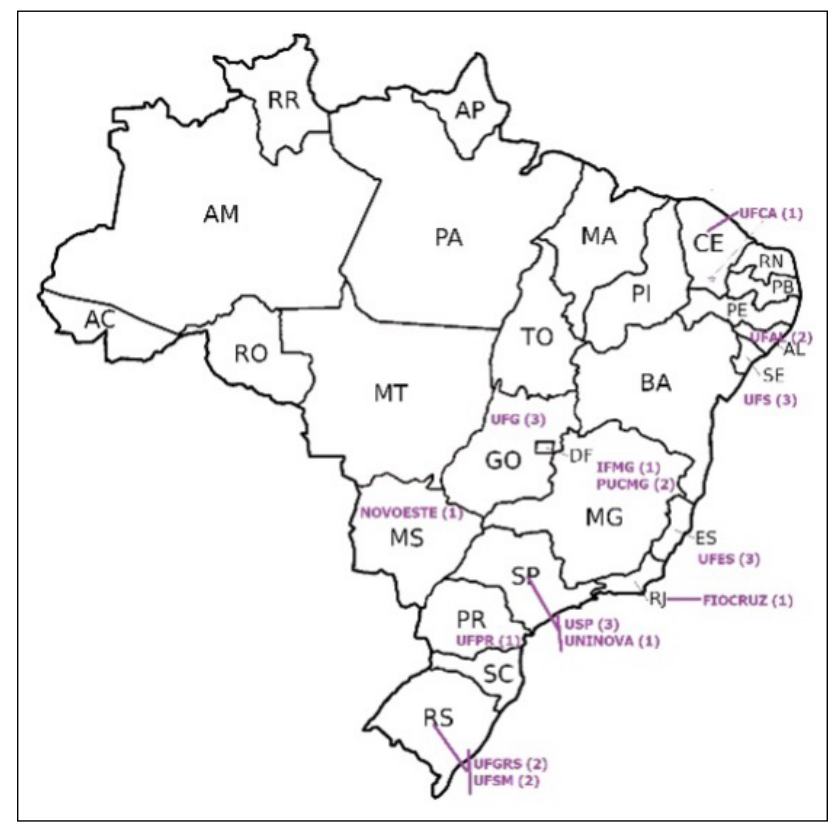

Figura 1. Mapa da publicação 2021 V10N1 - AtoZ 
Para completar e despertar o seu interesse, a entrevista com Patricia Pedri e Ronaldo Ferreira Araújo, ambos da Universidade Federal de Alagoas, esclarece o que é "Revisão por pares aberta". Na entrevista, eles explicam o contexto, as limitações, as vantagens e, entre outras coisas, comentam como a comunidade científica enxerga este tipo de avaliação. Além de apontarem quais as tendências e se as revistas brasileiras estão aderindo a este formato. Despertamos sua curiosidade? Se sim, corra e faça sua leitura do texto - se deseja saber mais, escreva para nós, conte-nos sua opinião.

Na seção de artigos encontramos nos artigos da primeira temática, que aborda os estudos qualitativos e quantitativos orientados à informação e ao conhecimento, estudos nas ciências agrárias, tecnológicas e da saúde. Temos uma análise bibliométrica da produção científica por unidade federativa brasileira em ciências agrárias que aponta a visão dos pesquisadores que buscam publicar em inglês na tentativa de visibilidade ou internacionalização. No campo de desenvolvimento de software, temos uma revisão sistemática de literatura que aborda a difícil tarefa de elicitação de requisitos a partir das necessidades dos usuários. Ainda uma análise de caso aplicado à gestão hospitalar que aponta a escassez de estudos relacionados à Gestão do Conhecimento nas organizações hospitalares, fato que distancia a gestão hospitalar de processos capazes de potencializar a produção de conhecimento e de promover a melhoria na tomada de decisão administrativa.

Recomendamos aos editores de revistas a discussão sobre visibilidade presente no artigo "Enhanced publications: um estudo da plataforma Public Library of Science (PLOS)" com argumentos incisivos sobre os ganhos de um periódico quando este recurso é implantado - desde a para a ascensão da comunicação científica, ampliação das publicações científicas, melhora na credibilidade das publicações, colabora para a legitimação das revistas científicas, potencialização da visibilidade dos envolvidos no processo de criação e produção de um periódico. O documento audiovisual é um dos tipos de produção recomendados, sendo o objeto do artigo "Documentação audiovisual na ciência da informação e ciências da comunicação". No artigo encontramos uma série de argumentos e recomendações de estudos envolvendo o campo histórico, social, cultural, político e tecnológico. Este formato permite o registro informacional na forma textual (verbal), iconográfica (imagem) e sonora (auditiva). O vídeo pôster já é uma realidade no Brasil desde 2013 e, por mais que os pesquisadores resistam, não tem mais volta (Freitas, Schmid, \& Tavares, 2014).

Na segunda temática "tecnologias aplicadas a sistemas, produtos e serviços de informação e de conhecimento" temos duas discussões importantes que merecem sua leitura. A primeira é uma análise documental do Facebook de um Sistema de Bibliotecas Públicas - como uma ação cultural com mídias sociais. O segundo artigo é uma sugestão de como calcular o engajamento informacional nas redes sociais. Estes se complementam e com certeza é de interesse para quem faz marketing por meio das redes sociais.

Finalizamos a seção com os artigos sobre a Gestão de Informação e do Conhecimento em organizações públicas, privadas ou de terceiro setor. Dividimos a apresentação em dois blocos de aplicação: engenharia e saúde.

Na engenharia temos um estudo de casos múltiplos sobre a Gestão do Conhecimento (GC) em Organizações Baseadas em Projeto (OBPs) realizados em empresas de engenharia de projetos industriais que permitem identificar as barreiras à GC e sua influência nos processos. O segundo é um estudo de caso sobre o impacto da gestão documental nos arquivos de engenharia e arquitetura de um instituto federal que permitiu a otimização dos processos de recuperação da informação, respeitando o perfil dos usuários da unidade.

Finalmente, o artigo que traz o relato da (re)configuração de projetos e ações de extensão universitária no enfrentamento da COVID-19 de uma universidade pública federal. Os projetos analisados apresentam indícios de inovação social originados pela motivação, finalidade, pauta, demanda e pelos resultados que culminaram em novas redes, projetos e programas.

O short paper "Desafios da comunicação pública e científica na promoção da saúde: estudo de caso do portal da UFPR" debate e analisa a divulgação científica com informações sobre a pandemia da Covid-19. Evidencia a necessidade de priorização das pautas de interesse público e o compromisso de difundir conhecimento científico sobre a pandemia que contribua com o direito universal à informação.

A leitura individualizada ou no todo do dossiê permite observar que a tecnologia presente em alguns artigos traz solução geradora de conhecimento a partir das análises com potencial para facilitar a vida da sociedade. A Revista AtoZ, como um produto informacional tecnológico, é um facilitador para vida cotidiana que impacta em múltiplas áreas e beneficia a sociedade propiciando: acesso a múltiplas fontes de conhecimento, estímulo à criatividade e inovação, estímulo à comunicação, entre outros. Como vocês perceberam, a interdisciplinaridade deste número é a tônica principal deste dossiê. Convidamos todos à leitura e à divulgação entre seus pares!

Boa leitura,

As Editoras.

Curitiba, março de 2021. 


\section{REFERÊNCIAS}

Freitas, M., Schmid, A. L., \& Tavares, S. F. (2014). Estratégia na comunicação científica na forma de vídeo pôster. In Administração, direito e tecnologia: a serviço da cidadania (pp. 220-246). Curitiba: Instituto Memoria. 